\title{
Microstructure and Wear Behaviors of Plasma-Sprayed MoAlB Ceramic Coating
}

\author{
Fuzhu Li ${ }^{1}$, Shengnan Sun ${ }^{1}$, Yong $\mathrm{Xu}^{2}{ }^{2}$, Lihui Tian ${ }^{3}$, Yun Wang ${ }^{1, *}$, Zhenying $\mathrm{Xu}^{1}$ and Ruitao $\mathrm{Li}{ }^{1, *} \mathbb{C}$ \\ 1 Department School of Mechanical Engineering, Jiangsu University, Zhenjiang 212013, China; \\ Lifuzhu@ujs.edu.cn (F.L.); shengnan.sun5@gmail.com (S.S.); xuzhenying@ujs.edu.cn (Z.X.) \\ 2 Department of Mechanic Engineering, Wenzhou Polytechnic, Wenzhou 325000, China; yongxu332@gmail.com \\ 3 National Demonstration Center for Experimental Materials Science and Engineering Education, \\ Jiangsu University of Science and Technology, Zhenjiang 212008, China; tianlihui3@gmail.com \\ * Correspondence: wangyun@ujs.edu.cn (Y.W.); RLI3@e.ntu.edu.sg (R.L.)
}

Citation: Li, F.; Sun, S.; Xu, Y.; Tian,

L.; Wang, Y.; Xu, Z.; Li, R.

Microstructure and Wear Behaviors of Plasma-Sprayed MoAlB Ceramic Coating. Coatings 2021, 11, 474. https://doi.org/10.3390/ coatings11040474

Academic Editor:

Armando Yáñez-Casal

Received: 23 March 2021

Accepted: 15 April 2021

Published: 18 April 2021

Publisher's Note: MDPI stays neutral with regard to jurisdictional claims in published maps and institutional affiliations.

Copyright: (c) 2021 by the authors. Licensee MDPI, Basel, Switzerland. This article is an open access article distributed under the terms and conditions of the Creative Commons Attribution (CC BY) license (https:/ / creativecommons.org/licenses/by/ $4.0 /)$.

\begin{abstract}
MoAlB ceramic coatings were prepared on a 316 steel surface by atmospheric plasma spraying with different arc power levels. The phase composition, microstructure and wear resistance of coatings against GCr15 and $\mathrm{Si}_{3} \mathrm{~N}_{4}$ counterparts were studied. The MoAlB ceramic decomposed and was oxidized to form $\mathrm{MoB}$ and $\mathrm{Al}_{2} \mathrm{O}_{3}$ during plasma spraying. With the increase of the arc power, MoAlB experienced more decomposition, but the coatings became denser. When the arc power increased from 30 to $36 \mathrm{~kW}$, the wear rates of coatings against GCr15 and $\mathrm{Si}_{3} \mathrm{~N}_{4}$ balls reduced by $91 \%$ and $78 \%$, respectively. The characterization of wear tracks shows that when against GCr15 counterparts, the main wear mechanisms are abrasive and adhesive wear, and when against $\mathrm{Si}_{3} \mathrm{~N}_{4}$ counterparts, fatigue and abrasive wear are dominant. The refinement of wear resistance by increasing arc power can be attributed to the improvement of density and adhesive strength among splats.
\end{abstract}

Keywords: MoAlB; plasma-sprayed coating; microstructure; tribological property

\section{Introduction}

316 stainless steel (316L) has been broadly used in mechanical components for its excellent mechanical properties and cost effectiveness [1,2]. However, the wear failure of components, which leads to great economic losses, is the main mechanical failure mode during service. Therefore, how to ameliorate the wear resistance of mechanical parts is an urgent problem. Ceramic coatings have been extensively studied as wearresistant layers, such as $\mathrm{WC}-\mathrm{WCoB}, \mathrm{WC}-\mathrm{Cr}_{3} \mathrm{C}_{2}-\mathrm{Ni}, \mathrm{NiCrBSi}-\mathrm{Zr}$ and $\mathrm{YSZ}$ coatings [3-6], which greatly ameliorated the friction performance of the metallic part. However, the wear resistance of these coatings is severely challenged by adverse industrial conditions. Therefore, researchers need to explore coatings with excellent tribological performance.

MoAlB ceramics are potential wear-resistant coatings for metal surfaces due to their outstanding mechanical properties [7-9] and wear performance, which have attracted much interest from researchers. For example, dense MoAlB ceramics prepared by highpressure sintering had excellent wear resistance, especially when the counterpart material was stainless steel $[10,11]$. This is due to the oxide film consisting of $\mathrm{MoO}_{3}, \mathrm{~B}_{2} \mathrm{O}_{3}$ and $\mathrm{Fe}_{2} \mathrm{O}_{3}$ formed on the friction surface, which has a good lubrication and protection effect, contributing to reducing the wear. The worn surface was more prone to oxidation and formed oxide film at $600{ }^{\circ} \mathrm{C}$, resulting in better wear resistance. Al matrix composites reinforced with MoAlB ceramic were prepared, and their tribological properties were investigated [12]. The results show that with the addition of MoAlB ceramic, the tribological properties improved greatly. Most notably, the wear rate of Al composites with 15 vol.\% MoAlB decreased by 95\% compared with pure Al. Tan et al. [13] also researched the friction performance of Mo-12Si-8.5B reinforced with MoAlB at room temperature (RT) $\left(1000{ }^{\circ} \mathrm{C}\right)$. 
Their results indicate that the wear resistance of the composites was significantly improved, which can be mainly attributed to the enhancement of hardness and the formation of oxide layers due to the addition of MoAlB ceramic. Thus, MoAlB ceramic is expected to ameliorate the wear resistance of 316L. However, until now, there has been no research on the preparation of MoAlB as a wear-resistant coating.

Atmospheric plasma spraying (APS) is an efficient method to fabricate coatings [14,15]. In such processes, the feedstock powder is heated and accelerated by plasma jet with a high temperature and velocity and then spread into splats on substrates. The coating is formed during the continuous deposition of splats $[16,17]$. Compared to other coating techniques, APS technology has high deposition efficiency. Therefore, APS is an appropriate technique for coating MoAlB powder. The performance of plasma-sprayed coatings is related to the size of the feedstock, the pretreatment of the substrate and spraying parameters. The effect of the size of the feedstock, arc power, spraying distance and the flow rate of secondary gas on the microstructure, porosity and bonding strength of $\mathrm{Ni} / \mathrm{Al}$ composite coatings was investigated by Zhang et al. [18]. The increase of power can enhance the density and bonding strength of the coating but results in phase transformation. The pretreatment of the substrate surface before plasma spraying is to increase the roughness and reduce the stress by sandblasting and preheating, respectively, which can enhance the bonding strength of the coating and the substrate. Otherwise, the coating is prone to cracking and chipping [19]. Moreover, previous studies have confirmed that MoAlB ceramic incongruently melts into $\mathrm{MoB}$ and $\mathrm{Al}_{2} \mathrm{O}_{3}$ at temperatures above $1435^{\circ} \mathrm{C}$ [20-22]. $\mathrm{MoB}$ and $\mathrm{Al}_{2} \mathrm{O}_{3}$ show high hardness and excellent wear resistance [23-26], which is expected to further improve the wear resistance. Therefore, we expect that the MoAlB coating prepared by APS will improve the durability of various tribological pairs, such as the friction surfaces of vehicle components, shafts, sleeves and tools [27,28].

In this study, APS was used to fabricate MoAlB ceramic coatings on 316L substrates, and the optimum processing parameters were identified. The microstructure and wear behavior of MoAlB coatings against GCr15 and $\mathrm{Si}_{3} \mathrm{~N}_{4}$ counterparts were investigated. Furthermore, the wear mechanisms were discussed in great detail.

\section{Materials and Methods}

\subsection{Fabrication of Feedstock Powder and Coatings}

The schematic of the preparation of MoAlB powder and coatings is exhibited below in Figure 1. In this study, commercially available molybdenum (Mo, $<2 \mu \mathrm{m}, 99.5 \%$, Rhawn, Shanghai, China), aluminum (Al, <30 $\mu \mathrm{m}, 99 \%$, Rhawn, Shanghai, China) and boride (B, $<20 \mu \mathrm{m}, 99 \%$, Rhawn, Shanghai, China) powders were used as raw materials. The Mo, $\mathrm{Al}$ and $\mathrm{B}$ powders were mixed in zirconia jars with a molar ratio of 1:1.5:1.3 [29] using a planetary ball mill (YXQM-2L, Changsha Miqi Instrument Equipment Co., Ltd., Changsha, China). Ball milling lasted $10 \mathrm{~h}$, the rotation rate was $300 \mathrm{rpm}$ and alcohol was used as the dispersing agent. The micrographs of raw powders were characterized by a scanning electron microscope (SEM, S-3400N, Hitachi Incorporation, Tokyo, Japan) and are shown in Figure 2. B powder was not characterized because of its strong oxidizability.

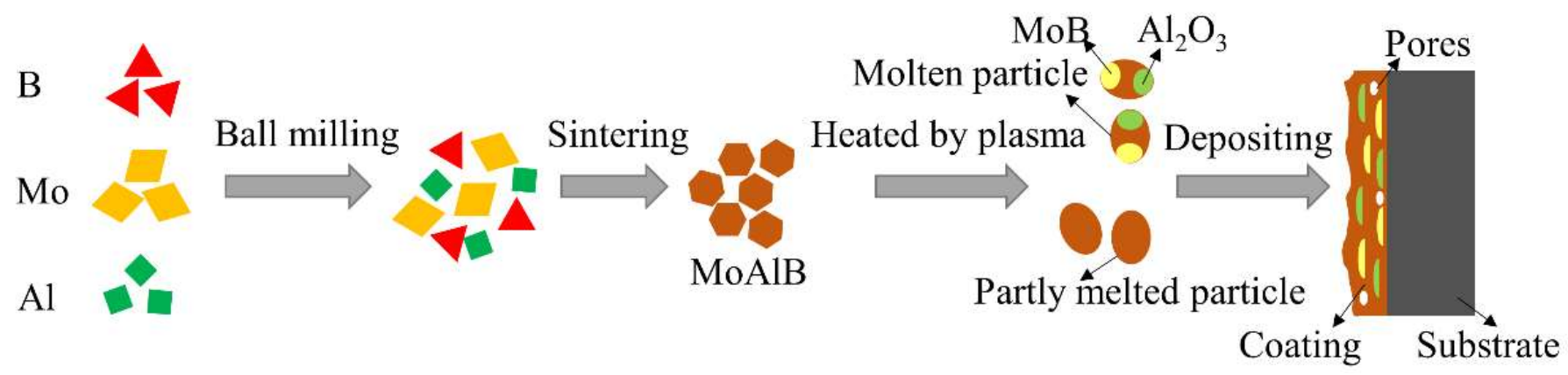

Figure 1. Schematic illustration of the fabrication process of the MoAlB coatings. 

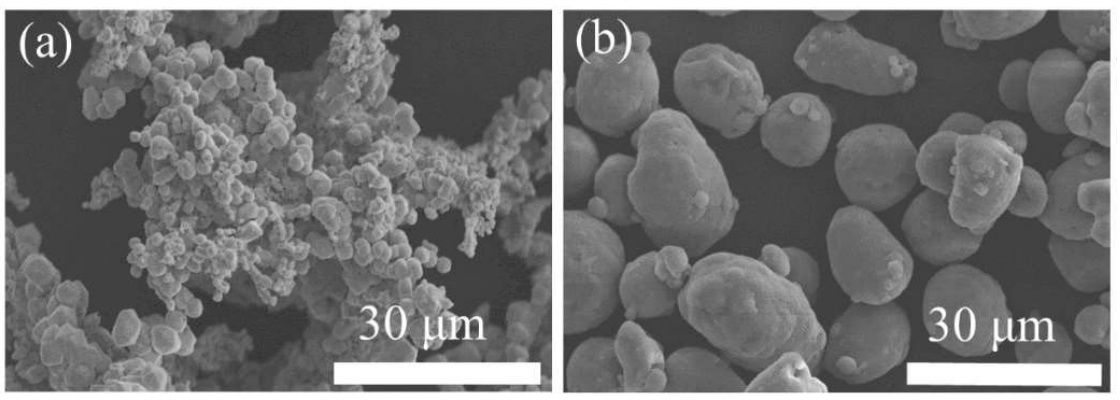

Figure 2. SEM morphology of the as-received powders: (a) Mo, (b) Al.

The mixture was dried at $100{ }^{\circ} \mathrm{C}$ for $12 \mathrm{~h}$ in a vacuum oven. After drying, the mixed powder was obtained and then heated in an $\mathrm{Al}_{2} \mathrm{O}_{3}$ crucible under flowing $\mathrm{Ar}$ at $1100{ }^{\circ} \mathrm{C}$ [30-32] for $6 \mathrm{~h}$ using an atmosphere furnace (AF1400, Kunshan Aikexun Machinery Co., Ltd., Suzhou, China) to form MoAlB ceramic. The block ceramics were crushed and milled at a speed of $300 \mathrm{rpm}$ for $1 \mathrm{~h}$ into MoAlB powder. In order to improve the flowability [33], the MoAlB powder was granulated using an aqueous solution of $5 \mathrm{wt} . \%$ polyvinyl alcohol (PVA) then dried in a vacuum oven at $100{ }^{\circ} \mathrm{C}$ for $5 \mathrm{~h}$. Finally, the powder with a particle size of 35-75 $\mu \mathrm{m}$ was sieved out using 200 and 400 mesh sieves for APS.

The MoAlB coatings were deposited on 316L substrates (diameter $=25 \mathrm{~mm}$, thickness $=5 \mathrm{~mm}$ ) using APS (XM-80SK, Shanghai Xiuma Spraying machinery company, Shanghai, China). The substrates were sand-blasted and preheated before spraying to realize the high mechanical bonding between the coatings and the substrates [34-36]. The currents of 500, 550 and 600 A were selected to study the effect of arc power on coatings [17,37], which were labeled as C-500, C-550 and C-600, respectively. Table 1 summarizes the deposition parameters.

Table 1. Plasma spraying parameters for MoAlB ceramic coatings.

\begin{tabular}{cc}
\hline Parameters & Values \\
\hline Arc power, $\mathrm{kW}$ & $30,33,36$ \\
Arc current, $\mathrm{A}$ & $500,550,600$ \\
Arc voltage, $\mathrm{V}$ & 60 \\
Primary gas (Ar), L/min & 45 \\
Secondary gas (H $), \mathrm{L} / \mathrm{min}$ & 6 \\
Powder feed rate, $\mathrm{L} / \mathrm{min}$ & 5 \\
Powder feed speed, $\mathrm{r} / \mathrm{min}$ & 2 \\
Spraying distance, $\mathrm{mm}$ & 70 \\
\hline
\end{tabular}

\subsection{Tribological Testing}

The tribological tests were conducted under dry sliding conditions using ball-on-disk friction and a wear tester (HT-1000, Zhongke Kaihua Science and Technology Development Ltd., Lanzhou, China) at RT and ambient humidity. During the wear test, the coated specimen was fixed on a rotating tray, and the abrasive ball was pressed against the coating surface by applied load, as illustrated in Figure 3 . The $\mathrm{Si}_{3} \mathrm{~N}_{4}$ ceramic balls and GCr15 steel balls with a diameter of $6 \mathrm{~mm}$ were employed as the counterpart balls $[10,11,13]$. Before each test, the coating was polished and then cleaned in anhydrous ethanol. The applied force, rotation diameter and sliding speed were $5 \mathrm{~N}, 6 \mathrm{~mm}$ and $0.17 \mathrm{~m} / \mathrm{s}$, respectively. The friction time of each parameter was $15 \mathrm{~min}$ and conducted three times to guarantee the accuracy of the results. 


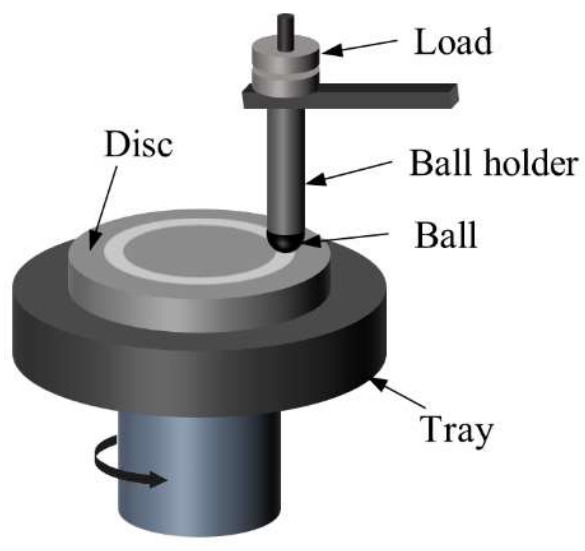

Figure 3. Schematic drawing of the ball-on-disk wear test.

\subsection{Characterizations}

The phase composition of the feedstock powders and the three coatings were inspected using X-ray diffraction (XRD, D8 Advance, Bruker Incorporation, Karlsruhe, Germany). The XRD was performed at the range of $10-80^{\circ}$ with a speed of $5^{\circ} / \mathrm{min}$. The microstructure of the powder, coatings and worn surfaces were examined by SEM combined with an energy-dispersive X-ray spectrometer (EDS, AZtecOne, Hitachi Incorporation, Tokyo, Japan). The porosities of the coatings were measured by imaging method using the Image J software (Image J, v1.8.0, National Institutes of Health, Bethesda, MD, USA).

The cross-section area of the wear tracks was examined by the confocal laser scanning microscope (keyencevk-x200, Keyence Co., Ltd., Osaka, Japan). The wear rate of the coatings was calculated from $\mathrm{W}=\mathrm{V} /(\mathrm{F} \times \mathrm{S})$, where $\mathrm{V}$ is the wear volume $\left(\mathrm{mm}^{3}\right), \mathrm{F}$ is the applied load $(\mathrm{N})$ and $\mathrm{S}$ is the total sliding distance $(\mathrm{m})$ [38].

\section{Results}

\subsection{Characterization of Powders}

Figure $4 \mathrm{a}, \mathrm{b}$ shows the morphologies of the mixed powders after ball milling. The $\mathrm{Al}$ powder became flaky with Mo and B powder homogeneously distributed on it. Figure $4 \mathrm{c}, \mathrm{d}$ shows that the MoAlB powder after granulation was polygonal in shape with a size distribution from 35 to $70 \mu \mathrm{m}$. The XRD pattern of the feedstock powder (Figure 5) revealed that the MoAlB ceramic was formed after sintering at $1100{ }^{\circ} \mathrm{C}[32,39]$ with some residual Mo phase.
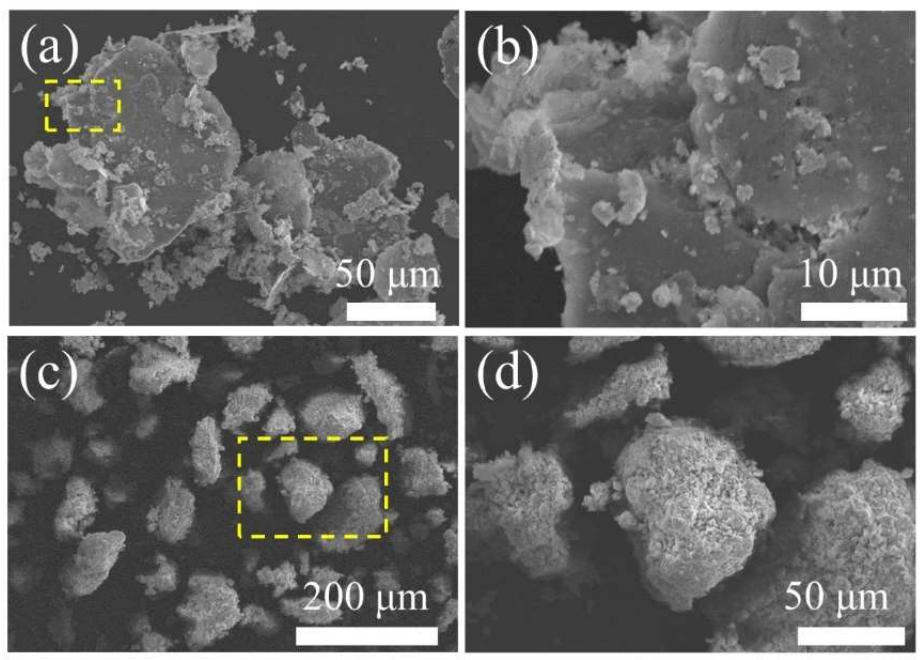

Figure 4. SEM micrographs of powders: (a,b) after ball milling; (c,d) after granulation. 


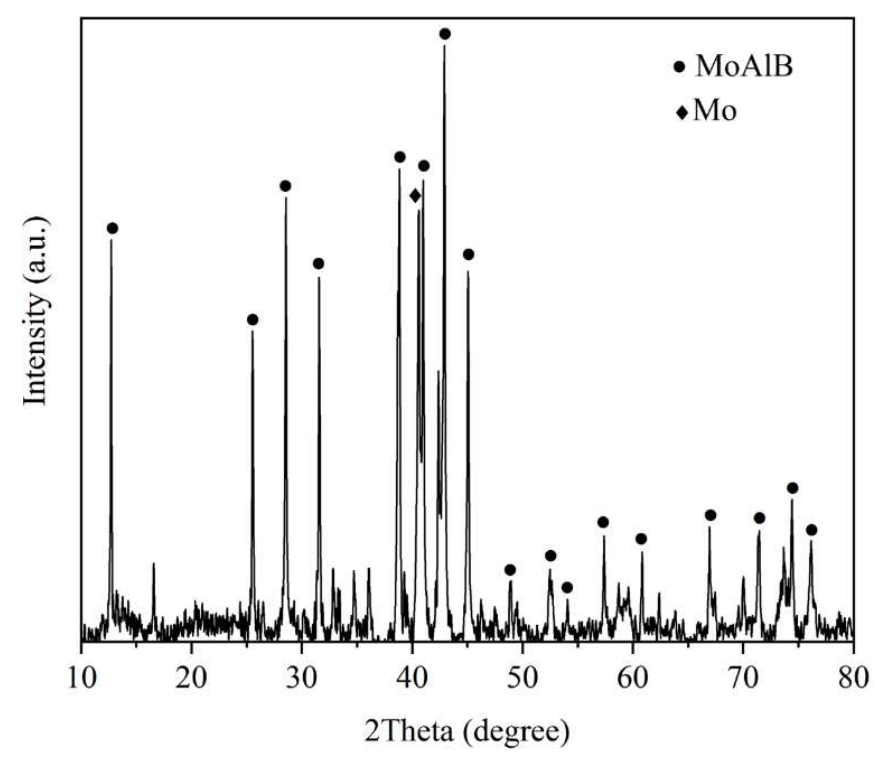

Figure 5. XRD pattern of the MoAlB powder.

\subsection{Microstructure of the Plasma-Sprayed MoAlB Coatings}

Figure 6 displays the XRD patterns of the MoAlB coatings deposited with different powers. The patterns reveal that $\mathrm{MoAlB}, \mathrm{MoB}, \mathrm{Mo}$ and $\mathrm{Al}_{2} \mathrm{O}_{3}$ phases were present in the three coatings, which indicates that the MoAlB ceramic partially decomposed and transformed into $\mathrm{MoB}$ and $\mathrm{Al}_{2} \mathrm{O}_{3}$ due to the higher temperature at the center position of the plasma than that at the edge $[21,22]$. However, the peak intensity of MoB in C-600 was significantly higher than those of C-500 and C-550, indicating that with the increase of

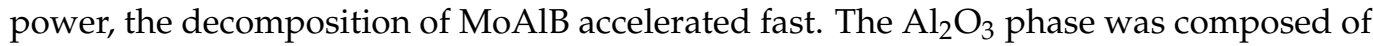
stable $\alpha-\mathrm{Al}_{2} \mathrm{O}_{3}$, metastable $\gamma-\mathrm{Al}_{2} \mathrm{O}_{3}$ and amorphous $\mathrm{Al}_{2} \mathrm{O}_{3}$ in the three coatings. This is in good agreement with the results reported by Misra et al. [40,41]. The content of $\gamma-\mathrm{Al}_{2} \mathrm{O}_{3}$ in the coatings rose with the arc power, which indicates that more MoAlB decomposed and suffered a rapid solidification during the deposition process [42].

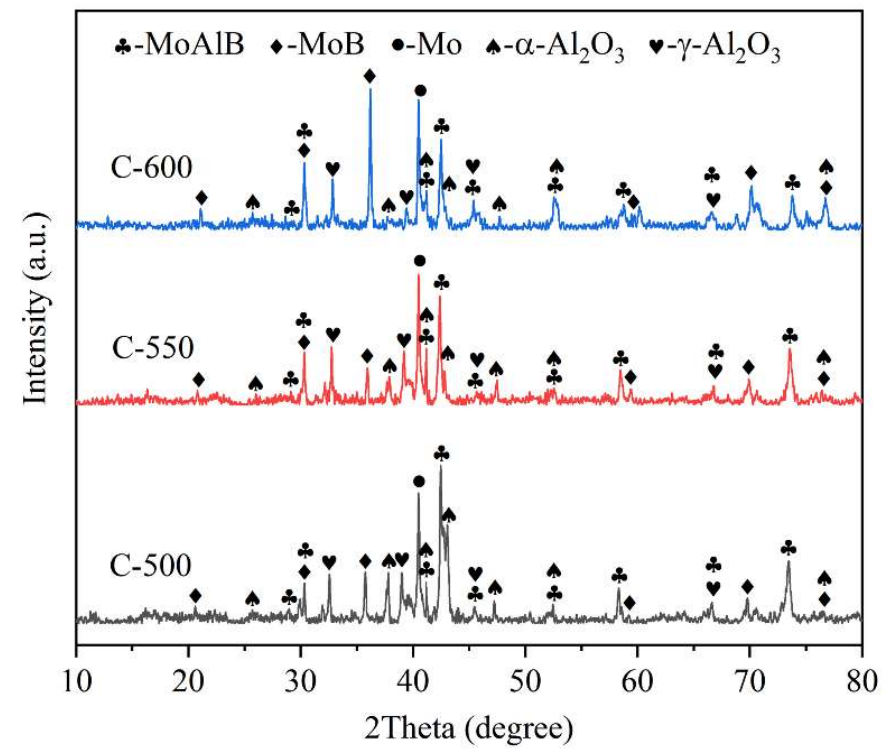

Figure 6. XRD patterns of as-sprayed MoAlB ceramic coatings with different powers.

Surface morphologies of the deposited MoAlB ceramic coatings with different spraying parameters are shown in Figure 7. The surfaces of C-500 and C-600 were mainly composed of unmolten or semimolten particles, with little completely molten powder, 
and the powder spreading was poor. Therefore, there were a large number of holes and pores formed in the coatings. The surface of C-600 showed full powder spreading with fewer semimolten particles, and the pores were smaller and fewer. These result in a denser coating with a stronger bonding strength $[40,43,44]$.
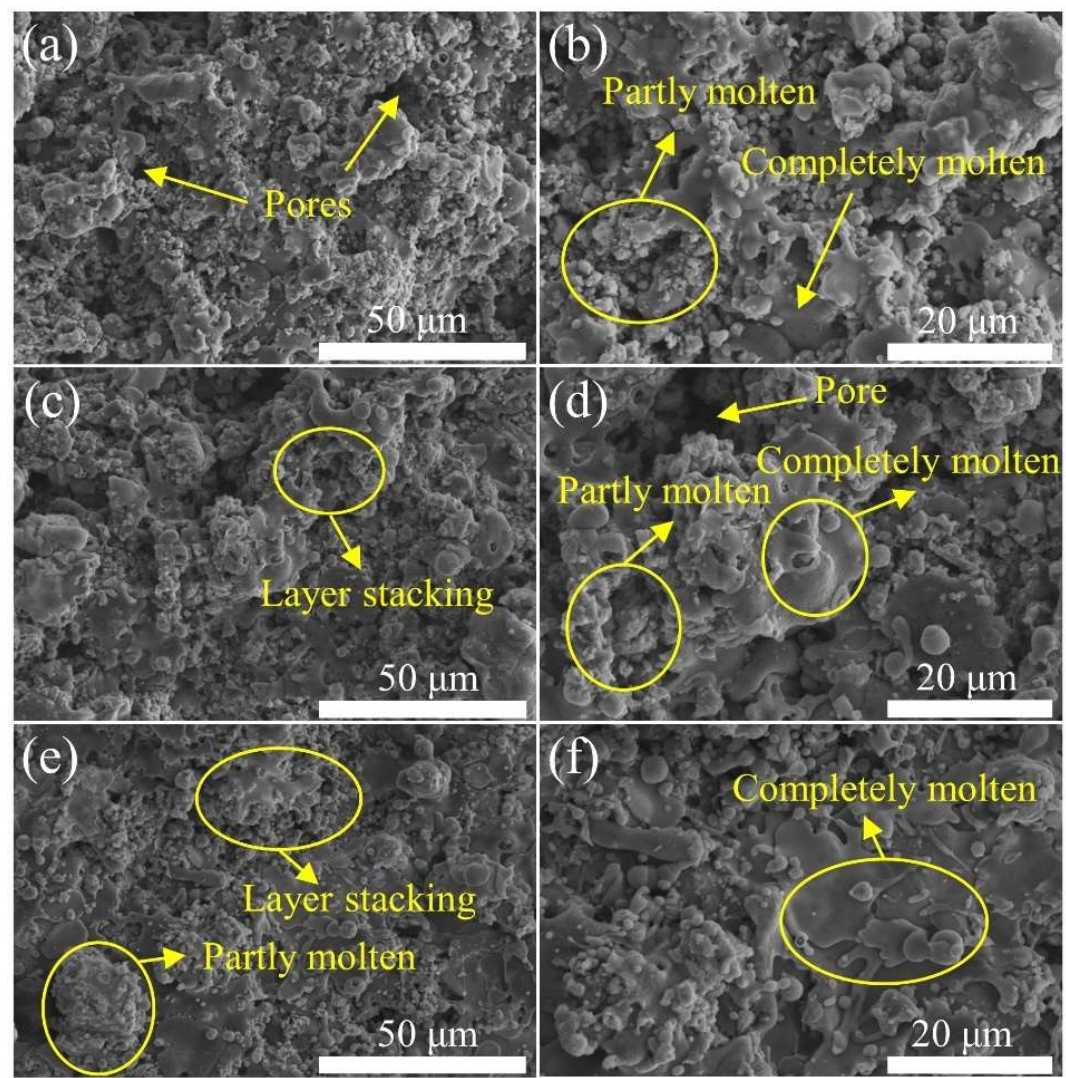

Figure 7. Surface micrographs of MoAlB coatings: (a,b) C-500; (c,d) C-550; (e,f) C-600.

Cross-sectional images of the MoAlB coatings sprayed with different arc power are shown in Figure 8. Coatings with a thickness of about $100 \pm 8.3 \mu \mathrm{m}$ were well bonded with substrates without evident concentrated cracks in the interfaces. Deep pores and unmelted particles can be observed in C-500 (Figure 8a,b). The formation of pores might account for the inadequate spreading during deposition and the spallation of splats in the course of polishing. Moreover, microcracks can be found in C-500 as a result of the tensile stress generated during deposition due to the inconsistent melting state of particles. The number of pores in C-550 significantly reduced, but unmelted particles and microcracks were still present. C-600 shows a typical lamellar structure (Figure 8e,f) due to the heavy deformation of the molten and partly molten powder during the deposition process. The deformation of droplets and the bonding between splats improved with the power, which is beneficial to the formation of a denser coating [45]. There were few pores in C-600 with a porosity of $1.94 \%$ compared to $9.26 \%$ of C-500 and $6.42 \%$ of C-550. This corresponded well with the morphology of the surface of C-600 presented in Figure 7e,f.

In order to observe the phase distribution in the coatings, the cross-section of C-600 was characterized by backscattered electron (BSE) imaging. BSE images of the cross-section of C-600 are presented in Figure 9, which reveal the presence of four distinct component contrasts in the coatings. According to the average atomic number of MoAlB, MoB, Mo and $\mathrm{Al}_{2} \mathrm{O}_{3}(20,23.5,42$ and 10, respectively) and the XRD patterns (Figure 6), it can be inferred that the areas with decreasing brightness in the BSE images correspond to Mo, $\mathrm{MoB}, \mathrm{MoAlB}$ and $\mathrm{Al}_{2} \mathrm{O}_{3}$, respectively. The $\mathrm{MoB}$ and $\mathrm{MoAlB}$ phases showed a layered structure with $\mathrm{Al}_{2} \mathrm{O}_{3}$ and some pores distributed around it. 

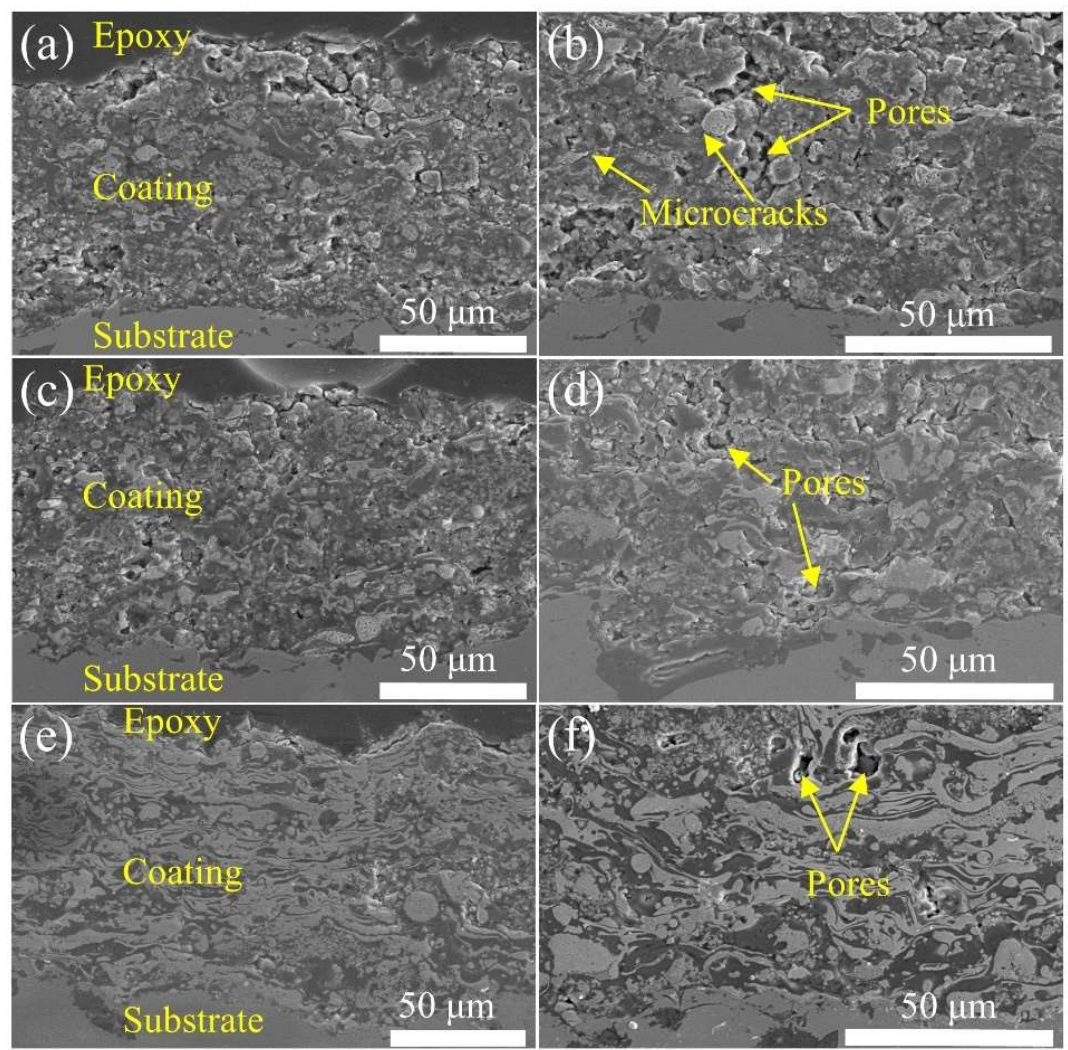

Figure 8. Cross-section of MoAlB coatings: (a,b) C-500; (c,d) C-550; (e,f) C-600.

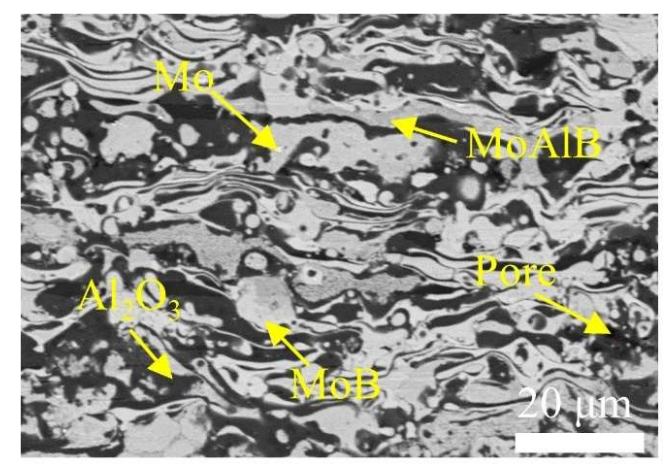

Figure 9. Backscatter SEM images of the cross-section of C-600.

\subsection{Tribological Properties}

Figure 10a,b displays the variation of the friction coefficients of various coatings with sliding time against GCr15 and $\mathrm{Si}_{3} \mathrm{~N}_{4}$ balls, respectively. The friction coefficients of both coatings reached a relatively stable stage after a short period of running-in. The stable friction coefficients against GCr15 varied (Figure 10a) in the range of 0.4-0.5. However, the friction coefficient curve of C-600 was steadier than those of C-500 and C-550. Large pores and unevenly distributed unmolten and partly molten particles in the coatings caused the fluctuation of the friction coefficient [46]. In contrast, C-600 is dense and the phases are uniformly distributed in lamellar structure [33], so the friction coefficient curve of C-600 was steadier. Figure 10b exhibits the friction coefficient curves of the three coatings against $\mathrm{Si}_{3} \mathrm{~N}_{4}$ counterparts. The average friction coefficients decreased with the arc power, and C-600 presented the lowest average friction coefficient of 0.46 . The friction coefficient curve of C-500 continued to rise after the running-in period and eventually stabilized at about 0.7 . 

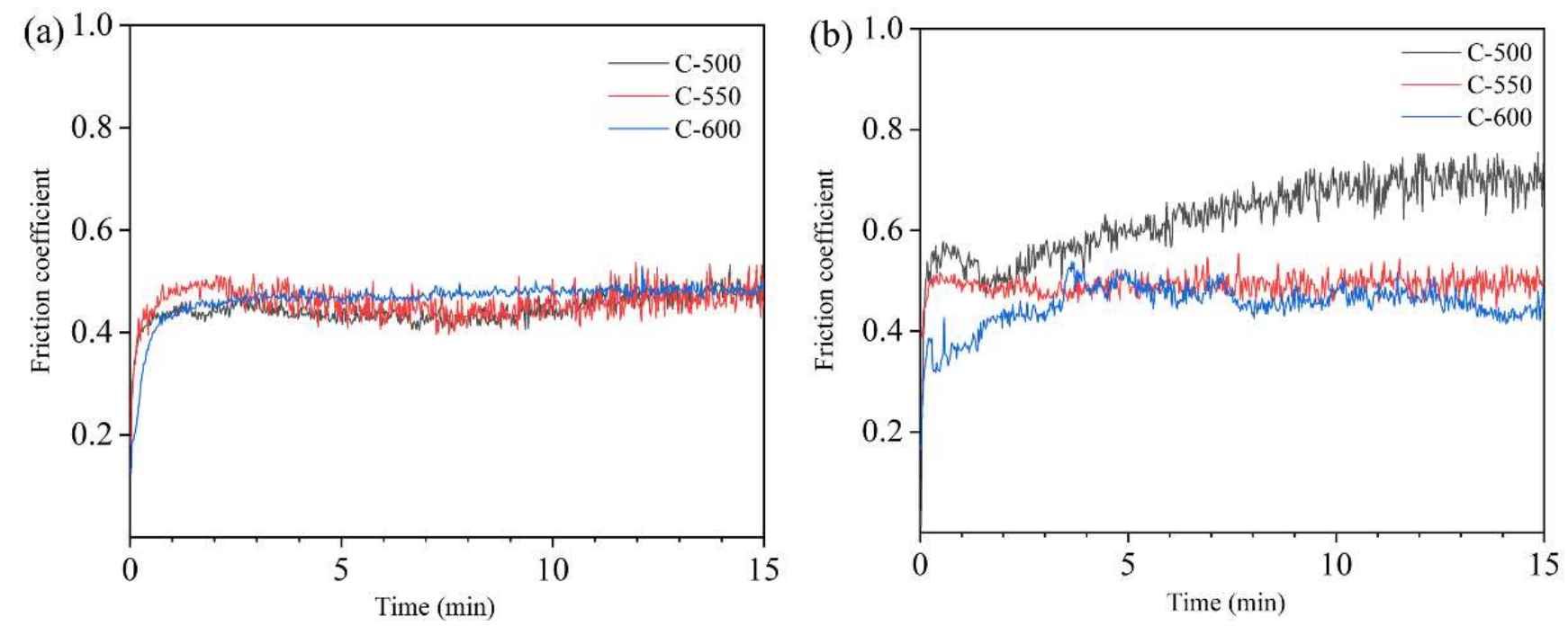

Figure 10. Friction coefficients of the MoAlB coatings: (a) against GCr15 counterparts; (b) against $\mathrm{Si}_{3} \mathrm{~N}_{4}$ counterparts.

Figure 11 displays the profile curves of wear tracks of the three coatings against GCr15 and $\mathrm{Si}_{3} \mathrm{~N}_{4}$ balls, respectively. It is obvious from Figure 11 that the depth of wear tracks gradually decreased with the arc power, and C-600 showed the lowest depth and width. The wear rates of the MoAlB coatings against GCr15 and $\mathrm{Si}_{3} \mathrm{~N}_{4}$ are presented in Figure 12. With the increase of power, the wear rate shows a significant trend of decrease. The wear rates of C-600 against $\mathrm{GCr} 15$ and $\mathrm{Si}_{3} \mathrm{~N}_{4}$ reach minimum values of $26.30 \times 10^{-5} \mathrm{~mm}^{3} \cdot \mathrm{N}^{-1} \mathrm{~m}^{-1}$ and $42.89 \times 10^{-5} \mathrm{~mm}^{3} \cdot \mathrm{N}^{-1} \mathrm{~m}^{-1}$, respectively. These results reveal that the wear resistance of the MoAlB coatings increased with the arc power. It can be attributed to the dense coating and high hardness and wear resistance of the decomposition phases. Moreover, the tribological behaviors of C-500 and C-550 against $\mathrm{Si}_{3} \mathrm{~N}_{4}$ counterparts were superior to those against GCr15 balls. However, the wear rate of C-600 against $\mathrm{Si}_{3} \mathrm{~N}_{4}$ was higher than that against GCr15, which corresponds well with the results of previous studies $[10,11]$.
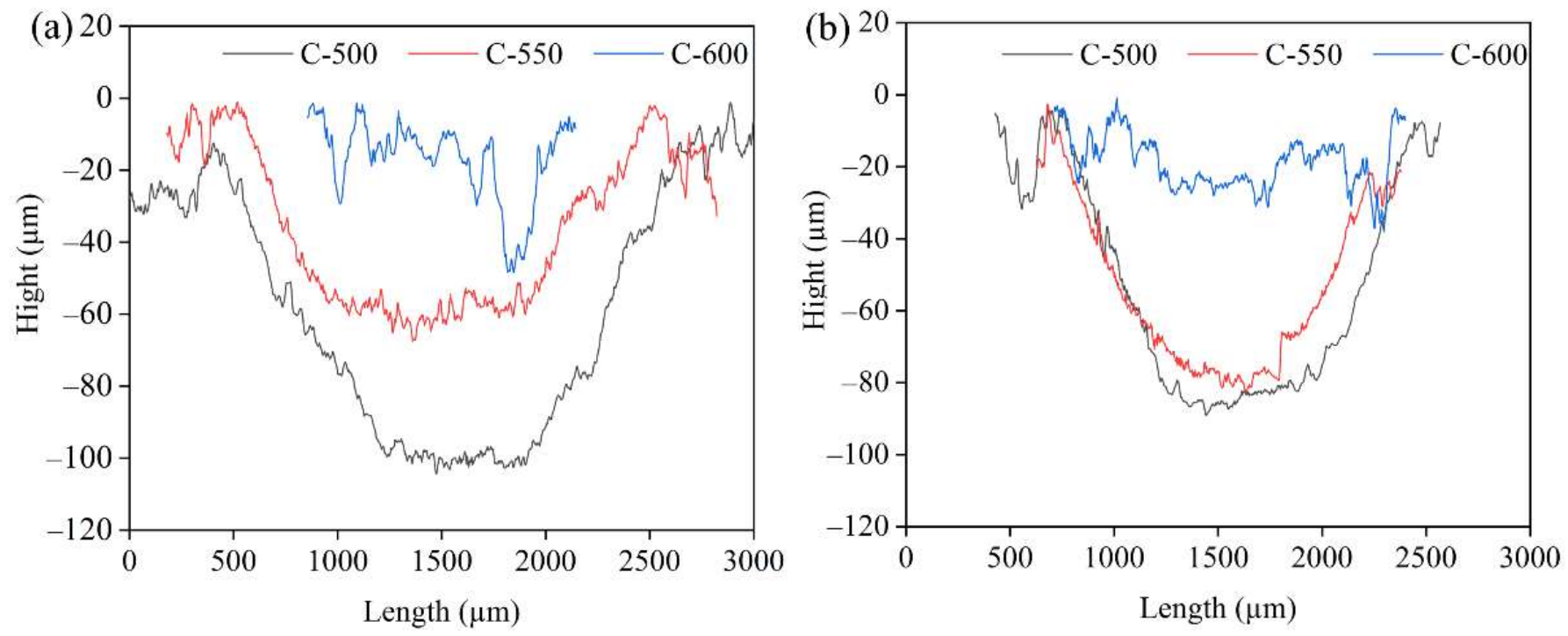

Figure 11. Profile curves of wear tracks of the coatings: (a) against GCr15 counterparts; (b) against $\mathrm{Si}_{3} \mathrm{~N}_{4}$ counterparts. 


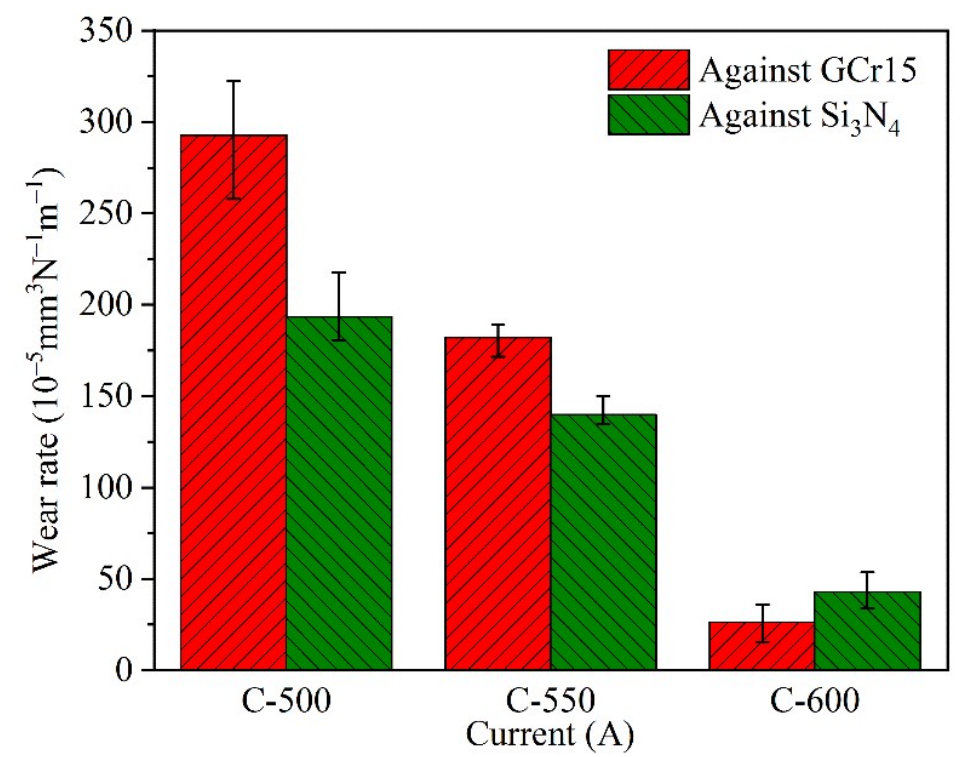

Figure 12. Wear rates of MoAlB coatings against $\mathrm{GCr} 15$ and $\mathrm{Si}_{3} \mathrm{~N}_{4}$ counterparts.

Surface images of the wear tracks of MoAlB coatings against GCr15 are shown in Figure 13. A lot of debris and small areas of the smooth surface were found on the wear tracks of C-500 and C-550, as shown in Figure 13a,c. Moreover, the high content of Fe, which was transferred from the GCr15 counterparts to the coatings, was found on the worn surface (Table 2). It is reasonable to conclude that the wear mechanism of C-500 and C-550 against GCr15 was mainly severe abrasive and adhesive wear. From the high-magnification image (Figure 13b,d), it can be seen that there were more cracks and pores on the smooth area of C-500 than that of C-550. However, the worn surface of C-600 (Figure 13e,f) displays larger areas of the smooth surface with some grooves, which is significantly different from C-500 and C-550. Moreover, the smooth areas consisted of Mo-Fe-Cr-O tribo-oxidative production (Table 2), which greatly improved the wear resistance of C-600. Therefore, the wear mechanisms were transformed from severe abrasive and adhesive wear to slight abrasive and adhesive wear as the power increased from 30 and $33 \mathrm{~kW}$ to $36 \mathrm{~kW}$. The differences of worn surfaces were possibly attributed to the different bonding strength between splats caused by the inconsistent melting and deformation of the powder. Severe abrasive wear of C-500 and C-550 was mainly caused by the weak interfacial bonding strength between the splats and high porosity. The particles in the coatings are easily dislodged to form debris, which aggravated the wear [33]. When the arc power improved, the deposited coatings were denser, and the bonding strength between particles was stronger, which could effectively protect the substrate from abrasion wear. Moreover, the content of $\mathrm{MoB}$ and $\mathrm{Al}_{2} \mathrm{O}_{3}$ rose with the arc power, and their high hardness and wear resistance contribute a lot to the enhancement of the wear resistance of the MoAlB coatings.

Table 2. Average chemical compositions of worn surfaces against GCr15.

\begin{tabular}{ccccccc}
\hline \multirow{2}{*}{ Element } & \multicolumn{2}{c}{ C-500 } & \multicolumn{2}{c}{ C-550 } & \multicolumn{2}{c}{ C-600 } \\
\cline { 2 - 7 } & wt.\% & at.\% & wt.\% & at. \% & wt.\% & at. \% \\
\hline Mo & 30.25 & 13.17 & 20.1 & 7.01 & 7.47 & 2.56 \\
$\mathrm{Al}$ & 10.32 & 14.40 & 9.3 & 11.53 & 3.83 & 4.41 \\
$\mathrm{O}$ & 16.67 & 40.39 & 26.25 & 54.85 & 24.08 & 50.78 \\
$\mathrm{Fe}$ & 40.83 & 30.63 & 43.06 & 25.78 & 63.21 & 41.30 \\
$\mathrm{Cr}$ & 1.92 & 1.42 & 1.29 & 0.83 & 1.41 & 0.95 \\
\hline
\end{tabular}



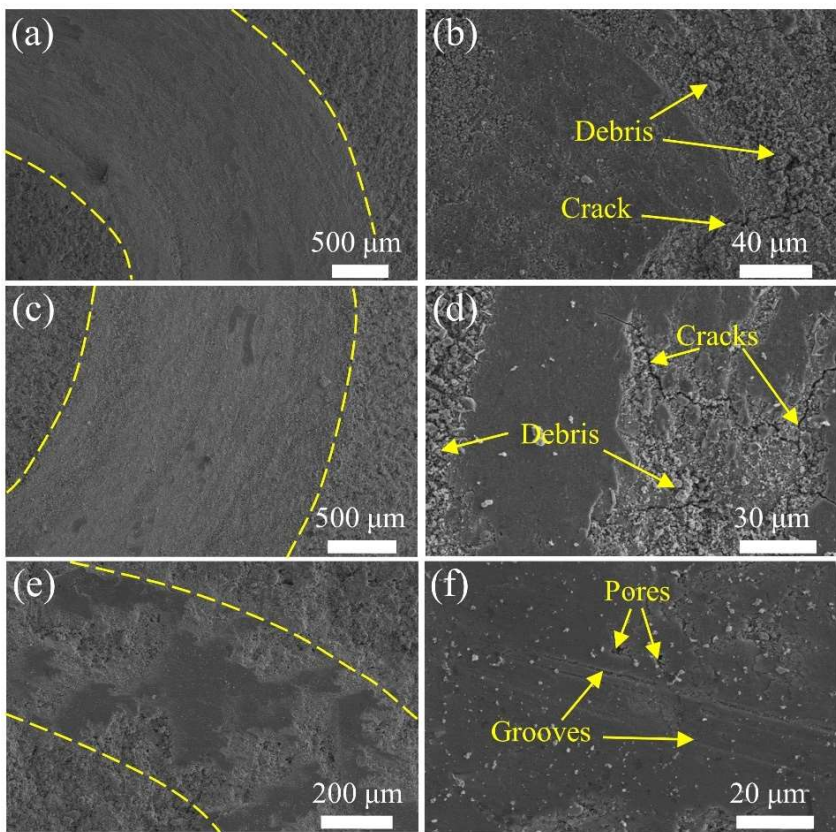

Figure 13. SEM images of worn surfaces against GCr15 counterparts: (a,b) C-500; (c,d) C-550; (e,f) C-600.

The wear track morphologies of the three coatings against $\mathrm{Si}_{3} \mathrm{~N}_{4}$ are significantly different from that against GCr15, as shown in Figure 14. The worn surfaces of the three coatings (Figure 14a,c,e) display delamination and fatigue cracks [47], which is the representative fatigue wear. Owing to the high hardness of $\mathrm{Si}_{3} \mathrm{~N}_{4}$ balls, some wear debris and particles were compacted to a form sheet attached to the worn surface, which retards the progress of wear. Moreover, from the EDS analysis results, it can be seen that there was a small amount of Si element on the worn surfaces (Table 3). However, more debris was observed from the worn surface of C-500 and C-550 (Figure 14b,d) than that of C-600 (Figure 14f). It is reasonable to conclude that the wear mechanism of MoAlB coatings against $\mathrm{Si}_{3} \mathrm{~N}_{4}$ was mainly abrasive and fatigue wear [14].
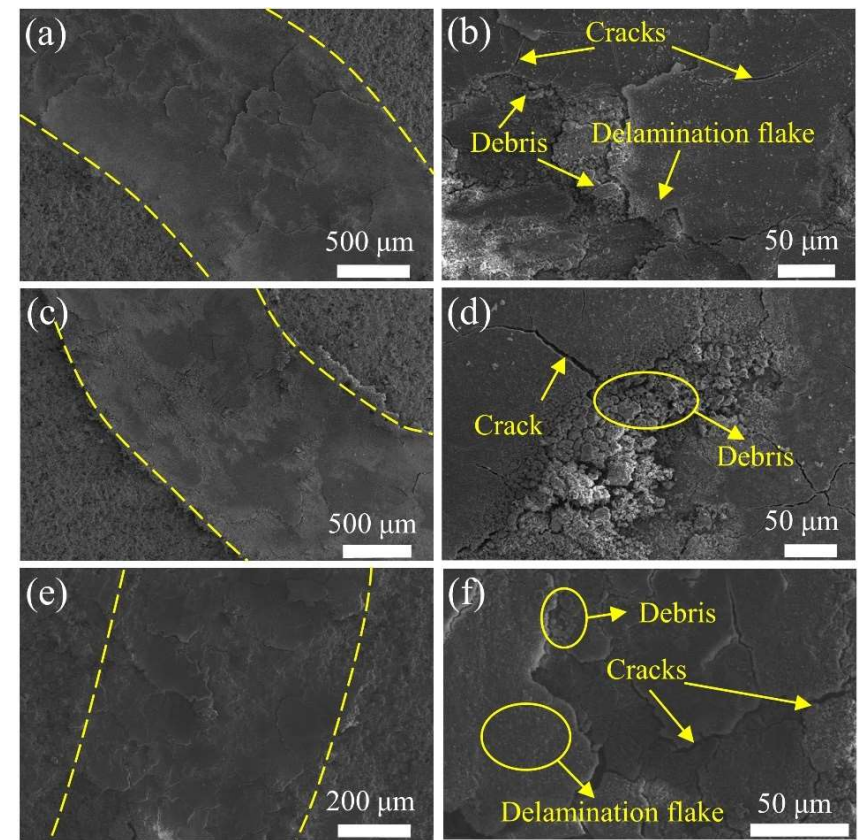

Figure 14. SEM images of worn surfaces against $\mathrm{Si}_{3} \mathrm{~N}_{4}$ counterparts: (a,b) C-500; (c,d) C-550; (e,f) C-600. 
Table 3. Average chemical compositions of worn surfaces against $\mathrm{Si}_{3} \mathrm{~N}_{4}$.

\begin{tabular}{ccccccc}
\hline \multirow{2}{*}{ Element } & \multicolumn{2}{c}{ C-500 } & \multicolumn{2}{c}{ C-550 } & \multicolumn{2}{c}{ C-600 } \\
\cline { 2 - 7 } & wt.\% & at. \% & wt.\% & at.\% & wt.\% & at.\% \\
\hline Mo & 43.74 & 14.16 & 59.65 & 30.34 & 59.42 & 23.93 \\
$\mathrm{Al}$ & 14.79 & 15.04 & 17.36 & 19.03 & 9.41 & 12.66 \\
$\mathrm{O}$ & 36.30 & 65.63 & 20.97 & 48.06 & 22.27 & 51.99 \\
$\mathrm{Si}$ & 5.18 & 5.17 & 2.02 & 2.57 & 8.91 & 11.42 \\
\hline
\end{tabular}

\section{Conclusions}

MoAlB coatings were deposited with different arc powers by APS technique. The phase composition, microstructure and wear behavior of the coatings were studied. The following conclusions were obtained:

1. The sprayed MoAlB coatings with different arc power levels consisted of MoAlB, $\mathrm{MoB}$ and $\mathrm{Al}_{2} \mathrm{O}_{3}$ phases. The MoAlB powder partly decomposed and was oxidized to form $\mathrm{MoB}$ and $\mathrm{Al}_{2} \mathrm{O}_{3}$. With the increase of power, the decomposition of MoAlB increased, and the compactness of the coatings and the bonding strength of splats increased greatly.

2. When MoAlB coatings slid against GCr15, the main wear mechanisms were changed from severe abrasive and adhesive wear to slight abrasive and adhesive wear as the arc power increased from 30 and $33 \mathrm{~kW}$ to $36 \mathrm{~kW}$. When the arc power increased to $36 \mathrm{~kW}$, the wear rate was the lowest $\left(26.30 \times 10^{-5} \mathrm{~mm}^{3} \cdot \mathrm{N}^{-1} \mathrm{~m}^{-1}\right)$.

3. The main wear mechanism of MoAlB coatings against $\mathrm{Si}_{3} \mathrm{~N}_{4}$ was abrasive and fatigue wear. The friction coefficient decreased with the arc power, and C-600 showed the lowest wear rate and presented excellent wear resistance. Moreover, $\mathrm{MoB}$ and $\mathrm{Al}_{2} \mathrm{O}_{3}$ with high hardness greatly improved the wear resistance of the MoAlB coatings.

Author Contributions: Methodology, S.S. and R.L.; validation, F.L. and Y.X.; resources, L.T. and Z.X.; data curation, L.T. and Z.X.; writing-original draft preparation, F.L. and S.S.; writing-review and editing, Y.X. and Y.W.; project administration, Y.W. and R.L. All authors have read and agreed to the published version of the manuscript.

Funding: This research was funded by the Research Foundation for the National Natural Science Foundation of China and Senior Talent Foundation of Jiangsu University, Grant Number 51575245, 51679112 and 18JDG030 respectively.

Institutional Review Board Statement: Not applicable.

Informed Consent Statement: Not applicable.

Data Availability Statement: Data is contained within the article.

Conflicts of Interest: The authors declare no conflict of interest.

\section{References}

1. Abbas, A.T.; Abubakr, M.; Hassan, M.A.; Luqman, M.; Soliman, M.S.; Hegab, H. An adaptive design for cost, quality and productivity-oriented sustainable machining of stainless steel 316. J. Mater. Res. Technol. 2020, 9, 14568-14581. [CrossRef]

2. Baltatu, M.S.; Vizureanu, P.; Sandu, A.V.; Munteanu, C.; Istrate, B. Microstructural analysis and tribological behavior of Ti-based alloys with a ceramic layer using the thermal spray method. Coatings 2020, 10, 1216. [CrossRef]

3. Lamuta, C.; Di Girolamo, G.; Pagnotta, L. Microstructural, mechanical and tribological properties of nanostructured YSZ coatings produced with different APS process parameters. Ceram. Int. 2015, 41, 8904-8914. [CrossRef]

4. Wang, H.; Yan, X.; Liu, X.; Lu, H.; Hou, C.; Song, X.; Nie, Z. Microstructure, mechanical and tribological properties of WC-WCoB coating. J. Eur. Ceram. Soc. 2018, 38, 4874-4881. [CrossRef]

5. Bhosale, D.G.; Rathod, W.S. Tribo-behaviour of APS and HVOF sprayed $\mathrm{WC}-\mathrm{Cr}_{3} \mathrm{C}_{2}-\mathrm{Ni}$ coatings for gears. Surf. Eng. 2020, 37, 80-90. [CrossRef]

6. Xiao, J.; Wu, Y.; Zhang, W.; Chen, J.; Wei, X.; Zhang, C. Microstructure, wear and corrosion behaviors of plasma sprayed NiCrBSi-Zr coating. Surf. Coat. Technol. 2019, 360, 172-180. [CrossRef] 
7. Su, X.; Dong, J.; Chu, L.; Sun, H.; Grasso, S.; Hu, C. Synthesis, microstructure and properties of MoAlB ceramics prepared by in situ reactive spark plasma sintering. Ceram. Int. 2020, 46, 15214-15221. [CrossRef]

8. Wang, S.; Xu, Y.; Yu, Z.; Tan, H.; Du, S.; Zhang, Y.; Yang, J.; Liu, W. Synthesis, microstructure and mechanical properties of a MoAlB ceramic prepared by spark plasma sintering from elemental powders. Ceram. Int. 2019, 45, 23515-23521. [CrossRef]

9. Xu, L.; Shi, O.; Liu, C.; Zhu, D.; Grasso, S.; Hu, C. Synthesis, microstructure and properties of MoAlB ceramics. Ceram. Int. 2018, 44, 13396-13401. [CrossRef]

10. Benamor, A.; Kota, S.; Chiker, N.; Haddad, A.; Hadji, Y.; Natu, V.; Abdi, S.; Yahi, M.; Benamar, M.E.; Sahraoui, T.; et al. Friction and wear properties of MoAlB against $\mathrm{Al}_{2} \mathrm{O}_{3}$ and 100Cr6 steel counterparts. J. Eur. Ceram. Soc. 2019, 39, 868-877. [CrossRef]

11. Yu, Z.; Tan, H.; Wang, S.; Cheng, J.; Sun, Q.; Yang, J.; Liu, W. High-temperature tribological behaviors of MoAlB ceramics sliding against $\mathrm{Al}_{2} \mathrm{O}_{3}$ and Inconel 718 alloy. Ceram. Int. 2020, 46, 14713-14720. [CrossRef]

12. Wang, Q.; Zhao, D.; Li, M.; Ren, F.; Duan, C.; Zhao, Z.; Chen, Y.; Wang, Y. Preparation and anisotropic tribological properties of MoAlB/Al laminated composites. Ceram. Int. 2021, 47, 5028-5037. [CrossRef]

13. Tan, H.; Sun, Q.; Zhu, S.; Cheng, J.; Wang, S.; Yang, J. High temperature tribological behavior of Mo-12Si-8.5B alloy reinforced with MoAlB ceramic. Tribol. Int. 2020, 150, 106344. [CrossRef]

14. Zhao, Y.; Wang, Y.; Yu, Z.; Planche, M.-P.; Peyraut, F.; Liao, H.; LaSalle, A.; Allimant, A.; Montavon, G. Microstructural, mechanical and tribological properties of suspension plasma sprayed YSZ/h-BN composite coating. J. Eur. Ceram. Soc. 2018, 38, 4512-4522. [CrossRef]

15. Babu, P.S.; Sen, D.; Jyothirmayi, A.; Krishna, L.R.; Rao, D.S. Influence of microstructure on the wear and corrosion behavior of detonation sprayed $\mathrm{Cr}_{2} \mathrm{O}_{3}-\mathrm{Al}_{2} \mathrm{O}_{3}$ and plasma sprayed $\mathrm{Cr}_{2} \mathrm{O}_{3}$ coatings. Ceram. Int. 2018, 44, 2351-2357. [CrossRef]

16. Wang, C.; Gao, P.; Liu, T.; Li, L.; Wang, E.; Wang, Q. Microstructure and wear performance of Ni-10 wt.\%Al coatings plasma sprayed on Ni-based superalloys with a sound field. Surf. Coat. Technol. 2019, 370, 157-162. [CrossRef]

17. Zhang, Z.; Lim, S.H.; Chai, J.; Lai, D.M.Y.; Cheong, A.K.H.; Cheong, K.L.; Wang, S.J.; Jin, H.; Pan, J.S. Plasma spray of Ti 2 AlC MAX phase powders: Effects of process parameters on coatings' properties. Surf. Coat. Technol. 2017, 325, 429-436. [CrossRef]

18. Zhang, L.; Liao, X.-J.; Zhang, S.-L.; Luo, X.-T.; Li, C.-J. Effect of powder particle size and spray parameters on the Ni/Al reaction during plasma spraying of Ni-Al composite powders. J. Therm. Spray Technol. 2021, 30, 181-195. [CrossRef]

19. Rodríguez-Barrero, S.; Fernández-Larrinoa, J.; Azkona, I.; De Lacalle, L.N.L.; Polvorosa, R. Enhanced performance of nanostructured coatings for drilling by droplet elimination. Mater. Manuf. Process. 2016, 31, 593-602. [CrossRef]

20. Kota, S.; Agne, M.; Zapata-Solvas, E.; Dezellus, O.; Lopez, D.; Gardiola, B.; Radovic, M.; Barsoum, M.W. Elastic properties, thermal stability, and thermodynamic parameters of MoAlB. Phys. Rev. B 2017, 95, 144108. [CrossRef]

21. Bei, G.; Van Der Zwaag, S.; Kota, S.; Barsoum, M.W.; Sloof, W.G. Ultra-high temperature ablation behavior of MoAlB ceramics under an oxyacetylene flame. J. Eur. Ceram. Soc. 2019, 39, 2010-2017. [CrossRef]

22. Kota, S.; Zapata-Solvas, E.; Chen, Y.; Radovic, M.; Lee, W.E.; Barsoum, M.W. Isothermal and cyclic oxidation of MoAlB in air from $1100{ }^{\circ} \mathrm{C}$ to $1400{ }^{\circ} \mathrm{C}$. J. Electrochem. Soc. 2017, 164, C930-C938. [CrossRef]

23. Basha, G.M.T.; Srikanth, A.; Venkateshwarlu, B. Effect of reinforcement of carbon nanotubes on air plasma sprayed conventional $\mathrm{Al}_{2} \mathrm{O}_{3}-3 \% \mathrm{TiO}_{2}$ ceramic coatings. Mater. Today Proc. 2019, 20, 191-194. [CrossRef]

24. Yang, K.; Li, J.; Wang, Q.; Li, Z.; Jiang, Y.; Bao, Y. Effect of laser remelting on microstructure and wear resistance of plasma sprayed $\mathrm{Al}_{2} \mathrm{O}_{3}-40 \% \mathrm{TiO}_{2}$ coating. Wear 2019, 426-427, 314-318. [CrossRef]

25. Zhu, L.; Zhu, Y.; Ren, X.; Zhang, P.; Qiao, J.; Feng, P. Microstructure, properties and oxidation behavior of $\mathrm{MoSi}_{2}-\mathrm{MoB}_{-} \mathrm{ZrO}_{2}$ coating for Mo substrate using spark plasma sintering. Surf. Coat. Technol. 2019, 375, 773-781. [CrossRef]

26. Zhang, P.; Guo, X.; Ren, X.; Chen, Z.; Shen, C. Development of Mo(Si,Al)2-MoB composite coatings to protect TZM alloy against oxidation at $1400{ }^{\circ} \mathrm{C}$. Intermetallics 2018, 93, 134-140. [CrossRef]

27. Kowalski, S. Failure analysis of the elements of a forced-in joint operating in rotational bending conditions. Eng. Fail. Anal. 2020, 118, 104864. [CrossRef]

28. Polvorosa, R.; Suárez, A.; de Lacalle, L.L.; Cerrillo, I.; Wretland, A.; Veiga, F. Tool wear on nickel alloys with different coolant pressures: Comparison of Alloy 718 and Waspaloy. J. Manuf. Process. 2017, 26, 44-56. [CrossRef]

29. Lu, X.; Li, S.; Zhang, W.; Yu, W.; Zhou, Y. Thermal shock behavior of a nanolaminated ternary boride: MoAlB. Ceram. Int. 2019, 45, 9386-9389. [CrossRef]

30. Chen, Y.; Kota, S.; Barsoum, M.W.; Radovic, M. Compressive deformation of MoAlB up to $1100{ }^{\circ}$ C. J. Alloys Compd. 2019, 774, 1216-1222. [CrossRef]

31. Rajpoot, P.; Rastogi, A.; Verma, U.P. Systematic investigation of structural, electronic, optical and thermal properties of ternary MoAlB; an ab initio approach. Mater. Res. Express 2018, 5, 025701. [CrossRef]

32. Shi, O.; Xu, L.; Jiang, A.; Xu, Q.; Xiao, Y.; Zhu, D.; Grasso, S.; Hu, C. Synthesis and oxidation resistance of MoAlB single crystals. Ceram. Int. 2019, 45, 2446-2450. [CrossRef]

33. Hashemi, S.M.; Parvin, N.; Valefi, Z. Effect of microstructure and mechanical properties on wear behavior of plasma-sprayed $\mathrm{Cr}_{2} \mathrm{O}_{3}$-YSZ-SiC coatings. Ceram. Int. 2019, 45, 5284-5296. [CrossRef]

34. Fernández-Abia, A.I.; Barreiro, J.; De Lacalle, L.N.L.; González-Madruga, D. Effect of mechanical pre-treatments in the behaviour of nanostructured PVD-coated tools in turning. Int. J. Adv. Manuf. Technol. 2014, 73, 1119-1132. [CrossRef]

35. Huang, C.; Yang, K.; Li, N.; Li, W.; Planche, M.; Verdy, C.; Liao, H.; Montavon, G. Microstructures and wear-corrosion performance of vacuum plasma sprayed and cold gas dynamic sprayed Muntz alloy coatings. Surf. Coat. Technol. 2019, 371, 172-184. [CrossRef] 
36. Huang, T.; Deng, C.; Song, P.; Lü, J.; Li, C.; Shu, Y.; Sun, B.; Ahmad, S.A.; Ji, Q.; Yi, J. Effect of the interface morphology and initial nanocrack on the fracture property of a ceramic reinforced plasma-sprayed coating. Ceram. Int. 2020, 46, 24930-24939. [CrossRef]

37. Venkateshwarlu, B.; Basha G, M.T.; Srikanth, A. Influence of critical plasma spray parameter on microstructural and tribo-logical characteristics of nanostructured tungsten carbide-cobalt coatings. Proced. Manuf. 2019, 30, 339-346. [CrossRef]

38. $\mathrm{Xu}, \mathrm{X}$; $\mathrm{Su}, \mathrm{F}$; $\mathrm{Li}, \mathrm{Z}$. Microstructure and tribological behaviors of $\mathrm{MoN}-\mathrm{Cu}$ nanocomposite coatings sliding against $\mathrm{Si}_{3} \mathrm{~N}_{4}$ ball under dry and oil-lubricated conditions. Wear 2019, 434-435, 202994. [CrossRef]

39. Kota, S.; Zapata-Solvas, E.; Ly, A.; Lu, J.; Elkassabany, O.; Huon, A.; Lee, W.E.; Hultman, L.; May, S.J.; Barsoum, M.W. Synthesis and characterization of an alumina forming nanolaminated boride: MoAlB. Sci. Rep. 2016, 6, 26475. [CrossRef]

40. Misra, V.C.; Chakravarthy, Y.; Khare, N.; Singh, K.; Ghorui, S. Strongly adherent $\mathrm{Al}_{2} \mathrm{O}_{3}$ coating on SS 316L: Optimization of plasma spray parameters and investigation of unique wear resistance behaviour under air and nitrogen environment. Ceram. Int. 2020, 46, 8658-8668. [CrossRef]

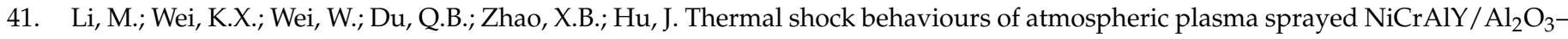
$20 \% \mathrm{TiO}_{2}$ gradient coating on $\mathrm{Cu}-\mathrm{Be}$ alloy. Surf. Eng. 2020, 36, 1113-1120. [CrossRef]

42. Deng, W.; Li, S.; Hou, G.; Liu, X.; Zhao, X.; An, Y.; Zhou, H.; Chen, J. Comparative study on wear behavior of plasma sprayed $\mathrm{Al}_{2} \mathrm{O}_{3}$ coatings sliding against different counterparts. Ceram. Int. 2017, 43, 6976-6986. [CrossRef]

43. Gou, J.; Zhang, J.; Zhang, Q.; Wang, Y.; Wang, C. Effect of Nano-Si ${ }_{3} \mathrm{~N}_{4}$ Additives and plasma treatment on the dry sliding wear behavior of plasma sprayed $\mathrm{Al}_{2} \mathrm{O}_{3}-8 \mathrm{YSZ}$ ceramic coatings. J. Therm. Spray Technol. 2017, 26, 764-777. [CrossRef]

44. Tillmann, W.; Khalil, O.; Baumann, I. Influence of direct splat-affecting parameters on the splat-type distribution, porosity, and density of segmentation cracks in plasma-sprayed YSZ coatings. J. Therm. Spray Technol. 2021, 1-13. [CrossRef]

45. Liu, C.; Sun, J.; Venturi, F.; Romero, A.R.; Hussain, T. Microstructure and wear performance of alumina/graphene coating on textured $\mathrm{Al}_{2} \mathrm{O}_{3} / \mathrm{TiC}$ substrate composites. J. Eur. Ceram. Soc. 2021, 41, 1438-1451. [CrossRef]

46. Xiao, J.; Li, T.; Wu, Y.; Chen, J.; Zhang, C. Microstructure and tribological properties of plasma-sprayed CoCrFeNi-based high-entropy alloy coatings under dry and oil-lubricated sliding conditions. J. Therm. Spray Technol. 2021, 1-11. [CrossRef]

47. Xi, H.-H.; He, P.-F.; Wang, H.-D.; Liu, M.; Chen, S.-Y.; Xing, Z.-G.; Ma, G.-Z.; Lv, Z.-L. Microstructure and mechanical properties of Mo coating deposited by supersonic plasma spraying. Int. J. Refract. Met. Hard Mater. 2020, 86, 105095. [CrossRef] 